\title{
La casa habitada. Educación religiosa intercultural y crítica
}

\author{
The inhabited house. Intercultural and critical religious \\ education
}

A casa habitada. Educação religiosa intercultural e crítica

\author{
Nelise Wielewski Narloch ${ }^{1}$ \\ Universidad Nacional
}

\begin{abstract}
Resumen
Este artículo tiene por objetivo establecer una relación entre pedagogía crítica y educación religiosa intercultural. Se basa en los aportes de la pedagogía crítica de Paulo Freire y el modelo de educación religiosa intercultural planteado por personas académicas de la Escuela Ecuménica de Ciencias de la Religión, de la Universidad Nacional. Adopta la metáfora indígena de la casa común como espacio habitado en el cual la educación religiosa tiene como misión generar procesos educativos orientados a la convivencia respetuosa desde la diversidad de creencias, espiritualidades y convicciones. Con tal fin, considera fundamental que en el aprendizaje exista una reflexión crítica sobre las situaciones que fueron, y son todavía, motivo de discriminación, homogenización y marginación social de grupos culturalmente diversos.
\end{abstract}

Palabras clave: Pedagogía crítica, educación religiosa intercultural, contextos multiculturales.

\begin{abstract}
This article aims to establish a relationship between critical pedagogy and intercultural religious education. It is based on the contributions of Paulo Freire's critical pedagogy and the model of intercultural religious education proposed by scholars from the Ecumenical School of Religious Sciences of the National University of Costa Rica. The article adopts the indigenous metaphor of the common house as an inhabited space in which religious education has the mission of generating educational processes oriented towards respectful coexistence based on the diversity of beliefs, spiritualities, and convictions. For this purpose, the existence of a critical reflection is deemed as fundamental in learning, a critical reflection on the situations that were, and still are, a cause of discrimination, homogenization, and social marginalization of culturally diverse groups.
\end{abstract}

Keywords: critical pedagogy, intercultural religious education, multicultural contexts

1 Profesora en la Escuela Ecuménica de Ciencias de la Religión - Universidad Nacional, Costa Rica. Posee maestría en psicopedagogía y doctorado interdisciplinario en Letras y Artes para América Central, con énfasis en Teología. ORCID: https://orcid.org/0000-0001-9877-6963. Correo electrónico: nelisesm20@gmail.com 


\begin{abstract}
Resumo
Este artigo tem por objetivo estabelecer uma relação entre pedagogia crítica e educação religiosa intercultural. Baseia-se nas contribuições da pedagogia crítica de Paulo Freire e o modelo de Educação religiosa intercultural proposto por pessoas acadêmicas da Escuela Ecuménica de Ciencias de la Religión, da Universidad Nacional. Adota a metáfora indígena da casa comum como espaço habitado no qual a educação religiosa tem como missão gerar processos educativos dirigidos à convivência respeitosa a partir da diversidade de crenças, espiritualidades e convicções. Com tal finalidade, considera fundamental que na aprendizagem exista uma reflexão crítica sobre as situações que foram, e são ainda, motivo de discriminação, homogeneização e marginalização social de grupos culturalmente diversos.
\end{abstract}

Palavras chave: pedagogia crítica, educação religiosa intercultural, contextos multiculturais

\section{Introducción}

Los mitos cosmogónicos de los pueblos originarios de Costa Rica hacen referencia a una casa común donde cohabitan y conviven todos los seres vivos. La metáfora de la casa común es uno de los mitos fundacionales. Para la cultura malecu, todos los elementos de la naturaleza tuvieron su origen en la casa sagrada a partir de una conversación en forma de sueño. El mito fundacional del pueblo ngäbe cuenta que el ser humano nació de las semillas de maíz, sembradas dentro de la casa, porque en ella había tierra buena. Cuatro colores de maíz formaron los cuatro grupos humanos que habitaron la casa del pueblo ngäbe y allí convivieron, con sus diferencias y esperanzas. Finalmente, Sibö, deidad/divinindad/ser supremo del pueblo bribri, organizó una gran fiesta para inaugurar el Ú-sure, la gran casa cósmica donde la divinidad había sembrado las semillas de maíz. Para el evento, invitó a todos los que trabajaron con él: animales, aves, plantas, espíritu de la montaña, y espíritus sobrenaturales, como también a la mamá y a la abuelita de la danta. Así fue como el mundo fue creado en forma de una casa cónica².

Esta metáfora de la casa común se propone aplicar al campo de la educación religiosa intercultural como modelo de convivencia y aprendizaje a partir de las diferencias. El establecimiento de la enseñanza de la religión (católica) en las escuelas públicas de Costa Rica -mediante la Ley N. ${ }^{\circ} 21$ de Rafael Ángel Calderón Guardia, del 10 de noviembre

2 Maria Eugenia Bosoli, antropóloga, socióloga y activista de derechos humanos, es una de las principales referencias sobre los pueblos indígenas de Costa Rica. Es una de las fundadoras de la antropología en Costa Rica, así como la primera mujer antropóloga del país. También Adolfo Constenla Umaña, filólogo y lingüista costarricense, especialista en las lenguas indígenas de la Baja Centroamérica, es uno de los especialistas más reconocidos sobre las lenguas del área americana intermedia. 
de 1940, planteó una modificación significativa al mapa sociorreligioso de Costa Rica y representó un daño a la estructura de la casa común.

Por otro lado, el 24 de agosto del 2015 se da el cambio en el Artículo 1 de la Constitución Política de Costa Rica -que ahora la define como un Estado pluricultural y multiétnico- exige la superación de las diversas formas de exclusión, de injusticia cultural y hegemonía institucional religiosa que han sido no solo toleradas, sino también promovidas desde los espacios pedagógicos. En este contexto, el presente artículo dirigido, al Primer Congreso Nacional de Educación Religiosa en Clave Intercultural, expone reflexiones sobre el vínculo entre la pedagogía crítica y el modelo educativo de la educación religiosa costarricense.

La diversidad de creencias y espiritualidades, así como de tradiciones multiculturales provenientes de la diversidad de pueblos que constituye esta nación, representa, en este aniversario, desafíos y posibilidades a la educación religiosa. Se sugiere una reflexión en torno a las pedagogías críticas y la pedagogía intercultural al modelo de la educación religiosa. Se parte de la idea de que los aportes de las pedagogías críticas y contrahegemónicas han sido, a lo largo de las últimas décadas, una herramienta necesaria para el análisis de la realidad y del quehacer de la educación costarricense, específicamente en el campo de la educación religiosa intercultural.

Esta propuesta toma como punto de partida los aportes de personas académicas e investigadoras de la EECR, quienes proponen claves para una educación religiosa intercultural, para superar la hegemonía de la iglesia católica que ha normalizado la educación religiosa de carácter monocultural costarricense. Además, no solo aporta reflexiones, sino también propone una nueva praxis educativa en el campo específico de la educación religiosa, para visibilizar y respetar la diversidad de expresiones religiosas de la que se compone la sociedad costarricense. Este artículo está dividido en tres partes; inicia exponiendo los presupuestos teóricos acerca de la pedagogía crítica y la educación religiosa intercultural. Luego describe los contextos interculturales y multirreligiosos de Costa Rica. Finaliza apuntando tareas para una educación religiosa intercultural y crítica.

\section{La pedagogía crítica y la educación religiosa intercultural. Presupuestos teóricos}

Dentro del campo pedagógico, el brasileño Paulo Freire (1921-1997) se convierte en una figura central; él insiste en la necesidad de sustituir los modelos educativos, hasta entonces vigentes, por nuevos modelos fundamentados en 
una reflexión crítica sobre la realidad, esta que es cercana a la vida cotidiana de la población del continente.

La trayectoria de vida de Paulo Freire estuvo caracterizada por encuentros interculturales. Sus polémicos planteamientos cuestionadores de los modelos pedagógicos desvinculados de la realidad social lo convirtieron en un autor de referencia durante la dictadura militar brasileña (1964-1983). En 1964 debió exilarse en Chile, donde permaneció hasta 1970. En este tiempo escribió su reconocida obra Pedagogía del oprimido3. En 1969 fue profesor invitado en la Escuela de Educación de la Universidad de Harvard. Entre 1970 y 1980, el Consejo Mundial de Iglesias en Ginebra le asignó un puesto como consultor; esta experiencia hizo que Freire abriera su entendimiento a las diferencias sociales y culturales, centrando su atención tanto en las condiciones de opresión en las que muchas personas vivían como en la ideología detrás del mismo acto opresor.

En la obra Pedagogía del oprimido (1970), Freire indica que la enseñanza no solo debe ser una disciplina para transmitir conocimientos; debe ser, también, una disciplina formadora de conciencia social, política, ética y estética. Esta consciencia, cuando puesta en práctica, lleva a una acción

3 Paulo Freire, La pedagogía del oprimido. $2^{\mathrm{a}}$ ed. (México: Siglo XXI, 2005) liberadora de distintas formas de opresión y dominación. La situación de pobreza y de desigualdad en América Latina y el Caribe lo llevan a afirmar que la estructura social no puede estar al margen del quehacer educativo. Al considerar a la persona docente como sujeto de transformación, por creer en la capacidad presente en cada profesional dentro del contexto educativo, Freire pone en evidencia el papel preponderante de la persona docente, no como transmisora de contenidos, sino como elemento clave para la formación de estudiantado crítico y comprometido con la transformación social.

La pedagogía del oprimido, como pedagogía humanista liberadora, tendrá pues, dos momentos distintos, aunque interrelacionados. El primero, en el cual los oprimidos van descubriendo el mundo de la opresión y se van comprometiendo, en la praxis, con su transformación y, el segundo, en que una vez transformada la realidad opresora, esta pedagogía deja de ser del oprimido y pasa a ser la pedagogía de los hombres en proceso de permanente liberación. ${ }^{4}$

La pedagogía crítica freiriana expone la intrínseca relación entre educación y cambio social. Pone énfasis en procesos que permiten la reflexión crítica y aquella comprometida con la realidad; una reflexión que permite apuntar situaciones de violencia, opresión, marginación

4 Paulo Freire, La pedagogía del oprimido, 55. 
y discriminación como parte de una percepción cultural homogénea, colonial y colonizadora. Al mismo tiempo, esta reflexión pone en evidencia el potencial protagónico de grupos que viven y padecen junto a estas situaciones.

Para Yors Guillermo Solís Vargas, docente de primaria del MEP, los modelos educativos del contexto educativo costarricense están dominados por instituciones, grupos investigadores, partidos políticos, que están manejando la educación desde sus propios intereses, estudios o puntos de vista hegemónicos. Estos modelos se fundamentan en la transmisión de conocimiento más que en la reflexión y la criticidad, como indica Solís cuando menciona la propuesta pedagógica crítica de Freire como un modelo alternativo y enfatiza sus alcances al formar personas con conciencia de su realidad y entorno social:

¿Qué tipo de profesional es quien sabe mucho de su profesión, pero a la hora de votar no sabe por quién hacerlo ni le importa? O quien es excelente en su especialidad, pero no puede crear o tener sensibilidad por el arte o la cultura; aquel que sabe mucho de su trabajo, pero roba, engaña, contamina el ambiente, maltrata a los animales o malgasta su salario en vicios, apuestas, negocios ilegales, etc. ${ }^{5}$

5 Yors Guillermo Solís Vargas. "Sobre la necesidad de incluir la pedagogía crítica de corte latinoamericano en el sistema educativo público de Costa Rica”, Ensayos pedagógicos 13, n. 1. (enero-junio 2018): 45.
De la misma forma en que Freire propone un modelo pedagógico crítico, que se fundamenta en las situaciones cotidianas emergentes que viven las personas, la conexión con la realidad, y las luchas para des-homogeneizar la educación, también estos mismos principios se encuentran presentes en el modelo de pedagogía intercultural. Ambos elementos parten del principio de que la educación es un medio de conocer, respetar, acoger, reflexionar y actuar, teniendo la diversidad cultural como espacio de convivencia y aprendizaje.

La educación religiosa en clave intercultural, como propuesta de modelo pedagógico para el contexto costarricense, ha sido motivo de reflexión entre personas académicas de la Escuela Ecuménica de la Universidad Nacional en los últimos diez años, con el propósito de superar el modelo homogeneizador vigente hasta la actualidad en este campo educativo. Esto, porque la educación religiosa, tal y como ha sido pensada en su origen y desarrollada en Costa Rica, ha reducido las posibilidades de intercambio cognitivo que generan el encuentro y la convivencia en la diversidad, y ha renunciado, deliberadamente, a educar para comprender críticamente los hechos religiosos ${ }^{6}$.

6 José Mario Méndez Méndez. "Presentación". Siwô' Revista de teología / estudios sociorreligiosos, 12(2). (2019). 
Auxiliadora Montoya, académica de la Escuela Ecuménica de la Universidad Nacional, apunta que el modelo de educación religiosa utilizado por décadas es homogeneizador: impone una forma única de ver el mundo, es regida por cánones morales con pretensión universal; un lenguaje que presenta la cultura cristiana como si fuera la única; una enseñanza doctrinal como eje que atraviesa los programas educativos, visualiza a los grupos docentes como misioneros enviados a evangelizar y adoctrinar, e impone el cristianismo, su visión de mundo y prácticas religiosas propias, propiciando, de esta manera, la segregación y exclusión de estudiantes provenientes de otras culturas, etnias y religiones?

Para la académica Katia Castro, posicionar en una única visión de mundo invalida la sinfonía de caminos existentes para encontrar el sentido de la vida, que es diverso y plural como lo son las culturas y las épocas históricas con sus particularidades, riquezas y limitaciones ${ }^{8}$ (Castro, 2019). Por otro lado, un modelo de educación religiosa que tenga la interculturalidad como clave es capaz de generar oportunidades

7 María Auxiliadora Montoya Hernández. "Hacia una educación religiosa en clave intercultural: recuperando la memoria". Siwô' Revista de teología / estudios sociorreligiosos 12(2). (2019): 89-103.

8 Kattia Isabel Castro Flores. "La Opinión Consultiva y los retos que se derivan para la educación religiosa en Costa Rica". Siwô'Revista de teología / estudios sociorreligiosos 12(2). (2019): 73-88. de convivencia y de procesos dirigidos a construir relaciones de equidad, de justicia y de respeto mutuo, donde todas las personas puedan expresarse en libertad y respeto 9 .

Es necesario señalar que el modelo de educación religiosa intercultural no se reduce al simple reconocimiento de la diversidad cultural en un salón de clase, tampoco al estudio comparado de las religiones, ya que los contextos educativos actuales son reconocidos como multiculturales -diversidad de culturas- y también multirreligiosos. Al considerar una escuela multicultural como aquella en la que conviven estudiantes con diferentes identidades culturales, ya sean nacionales o del extranjero, de diferentes expresiones religiosas, quienes poseen también tradiciones religiosas, compuestas de creencias y no creencias.

En el paradigma intercultural como principio rector de la educación religiosa, la diversidad es un elemento potenciador del quehacer de esta disciplina, porque refuerza la convivencia respetuosa y el aprendizaje a partir de la diversidad. Así lo expresa Mario Méndez:

El objeto de estudio, en este modelo intercultural, está constituido por las relaciones (re-ligaciones) del ser

9 María Auxiliadora Montoya Hernández. "Hacia una educación religiosa en clave intercultural: recuperando la memoria". 
humano (con el otro y la otra, con el mundo, con lo considerado sagrado), cargadas de significación y apoyo para la convivencia en la vida cotidiana. Es importante conocer los aportes de las religiones, espiritualidades, cosmovisiones y creencias al enriquecimiento de la convivencia y a la construcción de una cultura de paz. En el caso de la educación religiosa costarricense, es urgente superar la invisibilización a la que han sido sometidas las cosmovisiones de los pueblos originarios $\mathrm{y}$ afrodescendientes. ${ }^{10}$

Por este motivo, el reconocimiento constitucional del país como un Estado pluricultural y multiétnico acentúa la importancia de espacios que promueven la pedagogía intercultural, como es la transformación intercultural de la educación religiosa. Las prácticas y los espacios educativos relacionados con el campo religioso son propicios para promover un intercambio de saberes gracias a la diversidad que caracteriza a los seres vivos que habitan la casa común. ¿Y por qué propicios? Porque la religión, en sus infinidades de formas, prácticas y espiritualidades, constituye una dimensión intrínseca en el ser humano capaz de dar sentido a la vida y proporcionar re-ligaciones con su entorno.

10 José Mario Méndez Méndez. "Educación Religiosa en Costa Rica: confesionalidad, neutralidad, interculturalidad", Siwô' Revista de teología / estudios sociorreligiosos 8 n. 1 y 2. (2015): 243.
En este sentido, como ya indicaba Méndez (2015), la transformación intercultural de las prácticas educativas en el campo de la educación religiosa exige una renuncia al control de las creencias existentes. Esto no significa renunciar a las propias creencias y convicciones, más bien, como lo afirma acertadamente Raúl Fornet-Betancourt, ante "los derechos culturales que tenemos como propios, para que por esta contracción del volumen de lo que somos, puedan emerger en nosotros mismos contextos de acogida, espacios libres no ocupados, en los que el encuentro con el otro es ya, de entrada, experiencia de convivencia en su sentido fuerte". ${ }^{11}$

\section{Contextos multiculturales con-viviendo en la casa común}

Como los demás países mesoamericanos, la población costarricense está compuesta por diferentes grupos culturales, resultado de la diversidad presente en la región que se resistió y se resiste a la homogenización proveniente de los diferentes momentos históricos, iniciados con la colonización y perpetuados por las tendencias culturales globalizantes.

El Caribe costarricense es la región de referencia de la cultura afrodescendiente; sin embargo, San José es la provincia que concentra la mayor

11 Raúl Fornet Betancourt, Interculturalidad y religión. (Quito: Abya-Yala, 2007): 47-48. 
población afrodescendiente del país, también llamada negra, mulata y afrocostarricense. Los datos del censo nacional 2011 indican que en San José habitan 105981 personas, más del doble de la que tiene la provincia de Limón, cuya población es de 51344 . En términos relativos, el cantón central de Limón tiene el mayor porcentaje de afrodescendientes: el $26 \%$ del total de sus habitantes, seguido por Talamanca, con un $19 \%$. Puntarenas es la segunda provincia que, en términos relativos, tiene más afrodescendientes, 11,45 $\%$, solo superada por Limón con un $15,75 \%$. Los cantones de Garabito y Aguirre, en la provincia puntarenense, tienen, respectivamente, $16 \%$ y 13,6 $\%$ de la población afrodescendiente y ocupan el tercero y cuarto lugar en el ámbito nacional.

Uno de los principales aportes de la cultura afrocostarricense a la interculturalidad del país es su conexión con las religiones y espiritualidades de matriz africana que surgieron en muchos lugares de Latinoamérica y del Caribe. La ancestralidad y la oralidad son claves para la comprensión de la dimensión religiosa, compuesta por historias, ritos, símbolos y costumbres perpetuados de generación en generación. Este aspecto quedó evidenciado en la memoria del Congreso Latinoamericano de Religiones y Teologías Afrolatinoamericanas y Caribeñas, realizado en Limón Costa Rica, en junio de 2019 (ver actas).

Además, el país está compuesto por poblaciones indígenas provenientes de ocho grupos socioculturales distintos: cabécares, bribris, ngäbes, térrabas, borucas, huetares, malecus y chorotegas. Estos grupos habitan en veinticuatro territorios y seis tienen sus propios idiomas. A ellos se deben sumar las poblaciones indígenas migratorias, como los miskitos de Nicaragua y las de ngäbe buglé de Panamá, quienes vienen a Costa Rica para trabajar en la producción agrícola en distintas zonas del país. Aunque históricamente fueron pueblos perseguidos, colonizados, cristianizados primero por la fe católica $\mathrm{y}$, actualmente, por las congregaciones pentecostales, han tenido que luchar permanentemente por su sobrevivencia y desarrollar formas de resistencia. Muchos grupos han sido obligados a la resignación y al silencio, resultado de la exclusión y la invisibilización social a las que están expuestos. Hay que destacar las palabras de Rina Cáceres, directora de la Cátedra de Estudios de África y el Caribe (CEAC), al condenar la invisibilización que sufre esta población en la historia costarricense: "Esos vacíos, silencios y ausencias en la memoria histórica no son inocuos, todo lo contrario, fueron llenados con estereotipos. La ausencia de información sobre el pasado fue sustituida por un conjunto de valoraciones en las que 
el racismo encontró un espacio para germinar y crecer"12.

Otra riqueza a destacar en la diversidad cultural costarricense es la presencia de personas migrantes. En los últimos cuarenta años, con el advenimiento del sistema económico neoliberal a escala global, muchas de las personas, desterradas y excluidas de los beneficios de este modelo han tenido que buscar un lugar al que puedan irse. Los registros de la Dirección General de Migración y Extranjería (DGME) ${ }^{13}$ indican que el crecimiento de documentos de residencia acumulados en el caso de Nicaragua pasó de 221904 en el 2006 a 329066 en el 2016. También se destaca el crecimiento respecto de otras nacionalidades, procedentes del Triángulo Norte de Centroamérica (que pasa de 10527 en 2006 a 20283 en 2016), Colombia (de 11316 en 2006 a 26789 en 2016), Estados Unidos (de 8902 a 24201 en esos mismos años), Venezuela (de 1 350 a 7 692), procedentes de Europa (de 8958 a 19 683) y de Asia (de 8 902 a 15 852).

12 Entrevista concedida a Noticias UCR, el 20 de noviembre del 2017, acerca del documental sobre la historia de la migración afrocaribeña para enseñanza académica. https://www.ucr. ac.cr/noticias/2017/11/20/ucr-documenta-historia-de-la-migracion-afrocaribena-para-ensenanza-academica.html

13 Datos extraídos del Diagnóstico del Contexto Migratorio de Costa Rica 2017, elaborado por la Fundación Sociedad y Género.
El aporte proveniente de la migración está en la contribución a la producción nacional y a la creación de riqueza, como también, de acuerdo con Gustavo Gatica, académico de la Universidad Estatal a la Distancia (UNED), la riqueza en la variedad de costumbres, hábitos y prácticas que evidencian la diversidad humana. Riqueza como posibilidad de construir expresiones y creaciones humanas que aumentan el acervo cultural del país. Riqueza económica a partir del aporte con trabajo humano, pago de impuestos y contribuciones sociales al Estado costarricense. ${ }^{14}$

De esta forma, las comunidades afrocostarricenses, los pueblos indígenas y la población migrante hacen parte del contexto intercultural y multirreligioso de la población del país, conviviendo en la misma casa. A lo largo de la historia, estos grupos fueron marginalizados, discriminados $\mathrm{e}$, inclusive, asesinados. Fueron condenados a recluirse en a una esquina de la casa común, en barrios llamados marginales, en territorios usurpados y quemados, en comunidades olvidadas por la historia y por la agenda política. Estos grupos fueron obligados a buscar formas de sobrevivir ante la hegemonía cultural impuesta. Lo religioso se ha

14 Gustavo A. Gatica López. "Aportes de las personas migrantes y refugiadas a la creación de riqueza en Costa Rica”, Revista Rupturas, 8(1), (2017):63-92. 
convertido en soporte y alivio, o cómo interpreta el teólogo John Sobrino ${ }^{15}$, una forma de cargar con los sufrimientos que la historia les ha impuesto. En muchas ocasiones, la apertura de estas comunidades indígenas a lo religioso las ha dejado vulnerables y grupos fundamentalistas se han aprovechado de esta vulnerabilidad para someter y poner a su servicio, mediante creencias hegemónicas, las tradiciones ancestrales de dichas comunidades.

Este contexto multicultural de resistencia, luchas, conquistas y fracasos hace parte de los mitos y relatos que el historiador mexicano Miguel León Portilla llamó los vencidos de la historia. Representan una oportunidad de aprendizaje en la perspectiva de la educación religiosa intercultural crítica. Las personas migrantes, los grupos afrocostarricenses y los pueblos indígenas traen consigo formas diversas de convivir en la misma casa, la casa común.

La metáfora de la casa común es tan significativo que, el 24 de mayo de 2015, el papa Francisco la menciona en la carta encíclica Laudato si' (Alabado seas, mi Señor), proponiendo un modelo de ecología integral, ilustrada con la metáfora del mundo como la casa común. La novedosa y válida propuesta de Francisco estuvo siempre

15 John Sobrino, Jesucristo liberador. Lectura histórico-teológica de Jesús de Nazaret, $5^{\mathrm{a}}$ ed. (Trotta: Madrid, 2010). presente en la cosmovisión los pueblos indígenas. Los mitos fundacionales de los pueblos indígenas rescatan la integralidad de la creación, están vinculados con el entorno, la naturaleza, el territorio, el ambiente, demostrando que la tensión entre los diferentes elementos creados no significa apropiación ni destrucción, sino resultado de una convivencia real.

En síntesis, la diversidad presente en la población que habita y convive en Costa Rica ser un país multicultural. Las memorias históricas presentes en los mitos, cuentos, relatos de vida, canciones, juegos, objetos sagrados, rituales, comidas y costumbres constituyen elementos claves para los procesos educativos específicamente en el campo de la educación religiosa intercultural. Esta diversidad representa una gran oportunidad, no solo de aprendizaje, sino también de formación crítica de la realidad en la que vive una parte de la sociedad costarricense. Dentro de la casa común el espacio debe ser equitativo para todos los grupos que allí conviven.

\section{Aportes de la educación religiosa intercultural y crítica}

El aporte de la pedagogía crítica, unida al modelo de educación religiosa intercultural, representa una oportunidad en el campo educativo para romper con muros discriminatorios, 
perjuicios, estereotipos y todas las formas de homogenización religiosa. Por ende, la educación religiosa se convierte en un espacio para potenciar reflexiones y acciones entre los grupos y a favor de los que han sido marginados e invisibilizados por la sociedad costarricense. La educación religiosa intercultural, como modelo que apunta a procesos educativos encauzados a una educación desde la convivencia en la diversidad, no puede ser a-crítica ante las situaciones sociales que enfrentan varios sectores de la población, precisamente por su diversidad cultural.

Históricamente, en el ámbito educativo se han enfatizado aspectos folclóricos de las diversas culturas y tradiciones que integran la población costarricense. Sin embargo, se ha omitido o no se ha dado importancia en estos espacios a temas relacionados con la justicia y el derecho negado históricamente a estas poblaciones diversas. Por ejemplo, hace ruido y desentona una actividad escolar que resalta la discriminación que sufren las personas migrantes, los atropellos a los derechos indígenas y la ausencia de políticas en la atención a los grupos de afrocostarricenses. En vez de esto, se resaltan aspectos folklóricos como la música, la comida, los bailes, los trajes típicos; sin embargo, no se plantea romper con una especie de orden preestablecido colonial y subordinado.
La pedagogía crítica de Paulo Freire nace precisamente para hacer eco en los silencios históricos de injusticia y opresión en los que viven los grupos diversos y socialmente marginados. Pensar críticamente sobre la realidad conduce al personal docente de educación religiosa a cuestionar los modelos pedagógicos homogeneizantes y a adoptar nuevos modelos que permiten “interculturalizar" la educación.

El aporte de la pedagogía crítica insta a reflexionar sobre los intereses y la agenda de quienes promueven y mantienen los discursos homogeneizantes. El discurso político neoliberal busca mantener un orden social, que tiene relación estrecha con el orden del mercado en su forma de distribuir y organizar la producción de la riqueza según las leyes de oferta y demanda de la producción. Este sistema excluye a aquellos que no son aptos para responder y convivir en tal orden social preestablecido. Por otro lado, el discurso católico busca mantener la tradición, la doctrina y los valores, absolutizando una única forma de creer.

En nuestro país nos hemos sentido consternados por el asesinato de dos líderes indígenas: Sergio Rojas Ortiz, líder del pueblo Bribri y Jerhy Rivera Rivera, líder indígena Brörán de Térraba. Ambos asesinatos fueron resultado de disputas entre indígenas y usurpadores de tierras. Este hecho, 
vinculado con todos los atropellos al territorio, a la espiritualidad y a la cultura indígenas, afrocostarricense y de las personas migrantes confirma la necesidad de una educación promotora de la justicia y de la vida. De esta forma, las tradiciones presentes en la sabiduría y los mitos no son simples recursos metodológicos para enriquecer de las clases de religión, sino que constituyen temas de fondo para la educación religiosa.

La educación religiosa tiene potencial de ser generadora de cambio social mediante la sensibilización y reconocimiento de las espiritualidades y derechos negados desde los tiempos de la colonia. La pedagogía crítica aporta insumos a la educación en materia de religión que, en última instancia, conduciría a un replanteamiento integral de la disciplina que en vez de adoctrinar promueve el convivir, aprender y respetar a partir de las diferencias interculturales. Para una educación religiosa intercultural y crítica, es urgente romper con los vínculos económicos neoliberales y eclesiales históricamente establecidos y crear nuevos vínculos con la vida cotidiana de las personas estudiantes y su diversidad cultural, en un constante intercambio de saberes. Al visibilizar las diferencias, estas se transforman en un recurso educativo centrado en la persona y su contexto sociocultural y no en valores o preceptos vinculados a una única religión.
En síntesis, el compromiso de la persona docente de educación religiosa en su quehacer educativo debe ser con la vida y la dignidad de cada estudiante, a nivel personal y comunitario. En otras palabras, significa asumir procesos educativos que generan aprendizaje a partir de las diferencias y promueven reflexión sobre los derechos de las personas y grupos culturalmente marginados. Más que un "objeto de estudio" o ámbito de conocimiento, los mitos, narraciones, símbolos y prácticas en el modelo de educación religiosa intercultural deben llevar a una sensibilización activa, promotora de los derechos humanos. Con esto se quiere resaltar el vínculo entre aprender a partir de las diferencias y la promoción de los derechos de los pueblos con sus historias negadas.

\section{Conclusiones}

Celebrar el 80 aniversario de la educación religiosa en Costa Rica representa una oportunidad para discutir y reflexionar sobre una nueva perspectiva para esta en el contexto costarricense. Se hace necesario mirar hacia el pasado y hacer memoria de un camino recorrido, resignificar el presente y mirar para el futuro, creyendo en la educación promotora de nuevas formas de convivencias en la casa común. Esta convivencia acontece en el ámbito de la gran casa, donde las estructuras dañadas deben ser reconstruidas o sustituidas por otras que garanticen la fortaleza de la 
construcción. Es una tarea que implica diferentes actores sociales interesados y comprometidos con una educación religiosa plural y crítica.

La educación religiosa desde el modelo intercultural sugiere una vinculación con el Departamento de Interculturalidad que posee el MEP. Para este departamento, la educación intercultural implica la promoción de la formación de ciudadanas y ciudadanos plurales, respetuosos y promotores de los derechos humanos, capaces de trasformar los contextos comunales, locales, nacionales y globales mediante el diálogo, el reconocimiento y la valoración de la diversidad cultural de carácter étnico, nacional y generacional. Algo muy cercano a la propuesta de la educación religiosa intercultural, preocupada por valorizar las relaciones (re-ligaciones) del ser humano con su entorno, con las demás personas, con el mundo y con lo sagrado. Este vínculo posibilitaría el diálogo entre dos departamentos interesados en temas comunes que tienen la interculturalidad como base.

Por otro lado, las pedagogías críticas abren horizontes hacia el cambio social y la transformación de la sociedad para que sea inclusiva, favorezca la convivencia y el conocimiento de la pluralidad cultural de Costa Rica. Los profesionales de la educación deben ser expertos en muchos ámbitos relacionados con el quehacer pedagógico, y esto implica cultivar también una formación y reflexión crítica en temas de política, sociedad, cultura, ética y derechos. Esta formación les permitirá comprender lo religioso más allá de las religiones, rechazar todas las formas de discriminación y generar procesos educativos críticos y sensibles a las realidades humanas, ecológicas y culturales.

Finalmente, el modelo de educación religiosa intercultural propuesto amerita un cambio en el propio nombre de la disciplina. Desde su creación, la educación religiosa costarricense como disciplina estuvo relacionada con la religión católica desde su fundación. Enseñar religión ha significado a lo largo de las décadas adoctrinar en el catolicismo. Para una nueva forma de concebir la educación religiosa en clave intercultural y crítica, proponer un nuevo nombre para esta disciplina, además de un gesto simbólico, significaría empezar una nueva historia de la educación religiosa en Costa Rica, liberada del matiz colonizador, homogeneizador y doctrinario. Esta es una tarea que quedará pendiente para las personas profesionales que entienden lo religioso como dimensión humana expresado en tradiciones, representaciones, creencias, prácticas y símbolos. El proceso educativo visto de esta forma se torna un espacio de aprendizaje y convivencia con las diferencias que habitan la casa común. 


\section{Bibliografía}

Castro, C. E., Constenla, U. A., \& Blanco, R. A. 1993. Laca Majifijica. San José: Universidad de Costa Rica.

Castro Flores, Kattia. 2019. La opinión consultiva y los retos que se derivan para la educación religiosa en Costa Rica. Siwô'- Revista de teología / estudios sociorreligiosos, 12(2), 73-88.

Estrada Torres, José Víctor. 2012. Cosmovisión y cosmogonía de los pueblos indígenas costarricenses. San José: MEP.

Fornet Betancourt, Raúl. 2007. Interculturalidad y religión. Quito: Abya-Yala.

Freire, Paulo. 2005. La pedagogía del oprimido (2 ed.). México: Siglo XXI.

Gatica López, G. A. 2017. Aportes de las personas migrantes y refugiadas a la creación de riqueza en Costa Rica. Revista Rupturas, 8(1), 63-92. https://doi. org/10.22458/rr.v8i1.1974

Sobrino, John. 2010. Jesucristo liberador. Lectura histórico-teológica de Jesús de Nazaret (5. ${ }^{\mathrm{a}}$ ed.). Madrid: Trotta.

Méndez Méndez, J. 2019. Presentación. Siwô'-Revista de teología / estudios sociorreligiosos, 12(2).

Méndez Méndez, Mario. 2015. Educación religiosa en Costa Rica: Confesionalidad, neutralidad, interculturalidad. Siwô' - Revista de teología / estudios sociorreligiosos 8(1 y 2).

Méndez, José Mario. 2015. De la intromisión a la educación: descolonizar para educar. En Ensino religioso na educação básica: fundamentos epistemológicos e curriculares, coords. Adecir Pozzer, 53-66. Florianópolis: Saberes em diálogo.

Montoya Hernández, M. 2019. Hacia una educación religiosa en clave intercultural: recuperando la memoria. Siwô' - Revista de teología / estudios sociorreligiosos, 12(2), 89-103.

Solís Vargas, Yors Guillermo. 2018. Sobre la necesidad de incluir la pedagogía crítica de corte latinoamericano en el sistema educativo público de Costa Rica. Revista Ensayos pedagógicos 13(1) (enero-junio): 39-52. https://doi. org/10.15359/rep.13-1.2 